\title{
Effect of Sample Geometry and Aggregate Type on Expansion Due to Alkali-Silica Reaction
}

\author{
Noura Sinno, Medhat H. Shehata ${ }^{1}$ \\ Department of Civil Engineering, Ryerson University, Toronto, Ontario, Canada
}

\section{Highlights}

- Alkali leaching is higher in smaller samples.

- Cylindrical samples leached less alkalis compared to standard prisms.

- Cylindrical samples expanded more than standard prisms.

- Higher alkalis are released from aggregates to solutions of higher alkalinity.

- Cylindrical samples correlate better to field samples, especially for one of the two tested aggregates.

\begin{abstract}
Late expansions due to alkali-silica reaction were observed in field samples for some aggregates and supplementary cementing materials (SCM) combinations despite meeting the 2-year expansion criterion of the concrete prism test. This fosters research into the effect of sample geometry and aggregate reactivity on alkali leaching and the expansion of lab samples. Larger samples showed less leaching compared to standard prisms. Cylinders of $100 \mathrm{~mm}$-diameter showed higher expansion than $75 \mathrm{~mm}$-standard prisms; however, both sample shapes showed similar expansions for one tested aggregate when used with SCM. Alkali leaching from concrete samples and alkali release from some aggregates could lead to cylindrical samples having a higher expansion and better correlation to field samples compared to standard concrete prisms.
\end{abstract}

Keywords: Concrete prism test, Alkali leaching, Field samples, Laboratory testing, Cylindrical samples, Alkali release from aggregates.

\section{Introduction}

Alkali-silica reaction (ASR) has been studied since 1940 [1] and is described as a chemical reaction in concrete resulting in deleterious expansions and cracking. Reactive silica present in the aggregate reacts with the alkalis available in the concrete pore solution leading to the formation of an expansive gel [2-5]. The presence of moisture is required for the gel to swell and cause expansion. At relative humidity (RH) levels higher than $80 \%$, the expansion can be increased dramatically with a small change in moisture level [2]. If the expansive force of the gel is higher than the concrete tensile strength, cracks will start to form [6]. The use of supplementary cementing materials (SCM) showed a reduction in expansion [7-9]. The reduced expansion in the presence of SCM is proven through lab testing using the concrete prism test (CPT) described in the Canadian Standards Association, CSA A23.2-14A [10], and American Society for Testing and Materials, ASTM C1293 [11]. The concrete prism test is known to be the most reliable lab test to evaluate the reactivity of aggregates and the effectiveness of SCM. However, studies showed that the field expansions of large blocks at ages beyond 15 years were higher than expected based on the 2-year expansions obtained using CPT for some aggregates and SCM combinations [12,13]. At 10 years, Fournier et al. [14] found a pass/pass or fail/fail relationship between the 2-year expansions obtained using the CPT and the exposure blocks expansion data. However, at 15 years, some prisms that passed the CPT in the

\footnotetext{
${ }^{1}$ Corresponding author

Email address: mshehata@,ryerson.ca
} 
laboratory showed deleterious results in large blocks under field exposure [12,13]. Fournier et al. [13] showed that the CPT 2-year expansion limit criterion of $0.040 \%$ is not always indicative of the long-term field performance for some aggregates/SCM combinations.

One of the possible reasons that could lead to a discrepancy between the field and the CPT expansions is the excessive alkali leaching from prisms due to their smaller size compared to field samples. Many attempts have been made to reduce the leaching, such as increasing the diameter of the cylindrical samples, increasing the prisms' cross-section or decreasing the air-to-concrete ratio in the testing container [15-17]. The increased expansion observed with the cylinders of higher diameter was attributed partly to the lower air-to-concrete ratio compared to smaller diameter samples [15]. Bérubé et al. [15] attempted to reduce leaching by studying the effect of different leaching-protective materials for samples without SCM, such as silane-based sealer, plastic sleeve and aluminum foil. However, although the leaching was reduced, none of the protective measures was able to increase the expansion for the tested samples [15].

In addition to Portland cement or cementing materials, some aggregates contribute alkalis to concrete pore solution, which should be taken into consideration when building new structures [18,19]. Bérubé et al. [18] found that the aggregates can contribute from less than 0.1 to $3.4 \mathrm{~kg} \mathrm{Na} \mathrm{O}_{\mathrm{e}} / \mathrm{m}^{3}$ of concrete when soaked in alkaline solutions. For instance, in the case of Spratt, a highly reactive aggregate from Ottawa, Ontario, the alkali release was $0.01 \%$ per mass of aggregate or $0.06 \mathrm{~kg} \mathrm{Na}_{2} \mathrm{O}_{\mathrm{e}} / \mathrm{m}^{3}$ of concrete. For Sudbury, a moderately reactive aggregate, the alkali release was $0.17 \%$ per mass of aggregate or $3.08 \mathrm{~kg} \mathrm{Na} \mathrm{O}_{\mathrm{e}} / \mathrm{m}^{3}$ of concrete [18]. Moreover, it was also found that more release of alkalis was obtained in $0.7 \mathrm{M} \mathrm{NaOH}$ or $\mathrm{KOH}$ solutions compared to saturated lime solutions [18]. However, a study by Yujiang et al. [20] showed contradicting results having less alkalis released in $0.7 \mathrm{M} \mathrm{NaOH}$ and $\mathrm{KOH}$ solutions compared to saturated $\mathrm{Ca}(\mathrm{OH})_{2}$ solutions. Limited research has been carried out to understand the effect of the pore solution alkalinity on the alkali release characteristics of aggregates.

In terms of concrete tests for evaluating ASR, the orientation of the casting plane was shown to have an influence on ASR expansion. In the standard concrete prism test, measurements are taken along the longitudinal axis of the prisms, which is parallel to the casting plane. Smaoui et al. [21] showed that the expansion due to ASR is always greater in the direction perpendicular to the casting plane regardless of the consolidation method. This is likely due to the fact that the flat/elongated particles tend to orient themselves in the plane parallel to the casting plane leading to a larger surface area of the reactive aggregate in this plane [21]. Hence, a larger expansion in the direction perpendicular to the casting plane will be reached. This could also be due to the more porous and thus weaker interfaces in this plane caused by the trapped water under the aggregates [21]. For the same concrete mixtures and prism size, samples cast vertically showed higher axial expansion than prisms cast horizontally, as per the standard test method [21]. Moreover, Smaoui et al. [21] found that the higher the amount of flat/elongated particles of the coarse aggregate in the $5 \mathrm{~mm}$ to $10 \mathrm{~mm}$ fraction, the more the ratio of expansion perpendicular to the casting plane and expansion parallel to the same plane. Also, the longitudinal expansion of cylinders cast vertically reached higher values compared to that of the prisms, whether cast horizontally or vertically [21].

Although many attempts were made to reduce alkali leaching in laboratory testing, there is still disagreement on a standard method to enhance laboratory testing for ASR. This paper presents results from a study that investigates the effect of sample shape and geometry on alkali leaching and expansion in an attempt to identify the reasons behind the variations between expansions under laboratory and field conditions. These discrepancies were found mainly for samples with SCM. Hence, this study aims at testing two types of reactive aggregates with SCM since no previous study covered the impact of sample shapes and dimensions on the expansion of concrete with SCM. In addition, the effect of aggregate reactivity, alkali content, and its tendency to release alkalis into the concrete pore solution are evaluated and used to help explain differences between laboratory and field expansion results.

\section{Materials and Experimental Methods}




\subsection{Materials}

\subsubsection{Aggregates Properties}

Two coarse aggregates of different reactivity were used in this study, namely Sudbury and Spratt. The first aggregate, Sudbury, is a partially crushed gravel which is slightly metamorphic, consisting of greywacke, argillite, quartz-wacke and quartzite obtained from a gravel pit in Sudbury, Ontario [22]. Spratt is a coarse limestone, slightly siliceous with $9 \% \mathrm{SiO}_{2}$ obtained from a quarry in Ottawa, Ontario [22,23]. The concrete expansions obtained at one year using the CPT are $0.17 \%$ and $0.21 \%$ for Sudbury and Spratt, respectively. The fine aggregate used is a non-reactive natural sand (limestone) obtained from Caledon, Ontario. To be able to analyze the effect of casting direction on expansion, the flat and elongated particles test, as per MTO LS608, was performed on the two aggregates and the results are shown in Tables 1 and 2. Spratt aggregate has higher amount of flat and elongated particles (13.2\%) compared to Sudbury (10.2\%). Table 2 summarizes the physical properties of the two aggregates.

Table 1. Particle shape of the two coarse reactive aggregates used in this study.

Aggregate
Mixed
Passing $19.5 \mathrm{~mm}$ sieve and
retained on $13.2 \mathrm{~mm}$ sieve
retained on $9.5 \mathrm{~mm}$ sieve
$\begin{aligned} & \text { Passing } 9.5 \mathrm{~mm} \text { sieve and } \\ & \text { retained on } 4.75 \mathrm{~mm} \text { sieve }\end{aligned}$

*For each aggregate, the flat and elongated particles are shown to the left and the cubical particles to the right.

Table 2. Aggregates properties.

\begin{tabular}{ccccc}
\hline Aggregate & & Sudbury & Spratt & Non-Reactive Sand \\
\hline Bulk Relative Density & & 2.552 & 2.691 & 2.538 \\
\hline Absorption (\%) & & 0.56 & 0.52 & 1.30 \\
\hline \multirow{3}{*}{ Flat and Elongated (\% by mass) } & $13.2 \mathrm{~mm}$ & 5.1 & 9.9 & - \\
for portion retained on sieve & $9.5 \mathrm{~mm}$ & 4.7 & 17.3 & - \\
size & $4.75 \mathrm{~mm}$ & 20.7 & 12.4 & - \\
& Average & 10.2 & 13.2 & - \\
\hline
\end{tabular}

\subsubsection{Cementing Materials}

General use Portland cement (GU-PC) with an alkali content of $0.99 \% \mathrm{Na}_{2} \mathrm{O}_{\mathrm{e}}$ was used in this study in addition to two types of SCM: low-calcium fly ash (FA) and slag. In addition, a blended Portland cement 
made of $92 \%$ GU-PC and $8 \%$ silica fume (GUB-8SF) was used. The chemical compositions of the cementing materials are provided in Table 3.

Table 3. Chemical compositions of cementing materials ( $\%$ by mass).

\begin{tabular}{ccccc}
\hline Oxide & GU-PC & FA & Slag & GUB-8SF \\
\hline $\mathrm{SiO}_{2}$ & 19.54 & 57.0 & 37.0 & 26.26 \\
$\mathrm{Al}_{2} \mathrm{O}_{3}$ & 5.21 & 23.4 & 8.2 & 4.69 \\
$\mathrm{Fe}_{2} \mathrm{O}_{3}$ & 2.16 & 3.5 & 0.5 & 2.15 \\
$\mathrm{CaO}$ & 62.39 & 9.5 & 38.5 & 56.06 \\
$\mathrm{MgO}$ & 2.39 & 1.0 & 10.5 & 2.06 \\
$\mathrm{SO}_{3}$ & 4.03 & 0.1 & 2.7 & 4.08 \\
$\mathrm{Na}_{2} \mathrm{O}$ & 0.24 & 2.27 & 0.33 & 0.20 \\
$\mathrm{~K}_{2} \mathrm{O}$ & 1.14 & 0.66 & 0.52 & 1.13 \\
\hline Loss on Ignition & 2.36 & 0.59 & 2.1 & 2.61 \\
\hline Total & 99.46 & 98.02 & 100.35 & 99.24
\end{tabular}

\subsection{Experimental Procedure}

\subsubsection{Expansion Samples}

Samples with different geometry and dimensions were cast in this research: prisms $(75 \times 75 \times 285 \mathrm{~mm})$, cylinders (ø 100 by $285 \mathrm{~mm}$ : same height as the prisms to allow measurements using the same length comparator) and $150 \mathrm{~mm}$ cubes. The molds used for the cylinders and cubes are not commercially available as there is no current test method that uses these sample shapes/sizes for monitoring length change. The molds were fabricated at Ryerson University and are shown in Fig. 1 and Fig. 2.

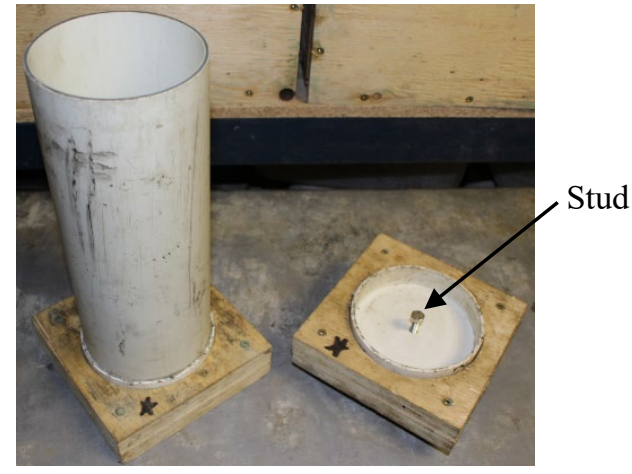

(a)

Fig. 1. Molds for (a) cylinders and (b) cubes [24].

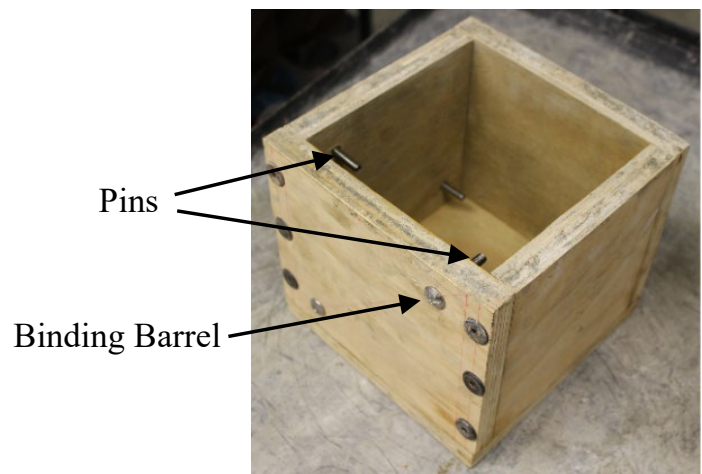

(b)

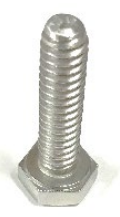

(a)

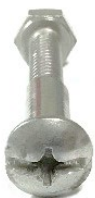

(b)

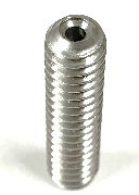

(c)

Fig. 2. (a) Studs for cylinders/prisms, (b) binding barrels to secure the studs/pins, and (c) pins for cubes. 
Measurement of the cylinders was done in a similar way to the prisms using the same length comparator, as shown in Fig. 3(a). For the cubes, expansion was measured diagonally using a DEMEC style digital strain gauge, as shown in Fig. 3(b). Measurements of the samples were taken until 2 years and the reported expansion is the average of three specimens obtained from the same mix.

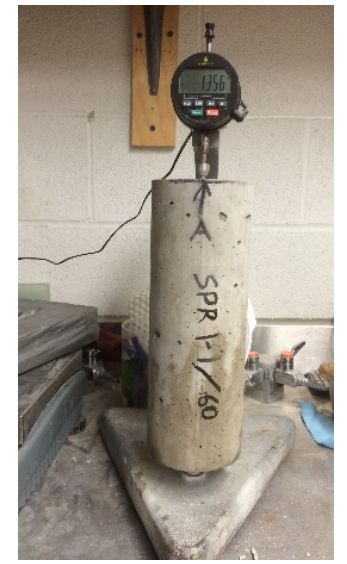

(a)

Fig. 3. Measurements of (a) cylinders and (b) cubes [5].

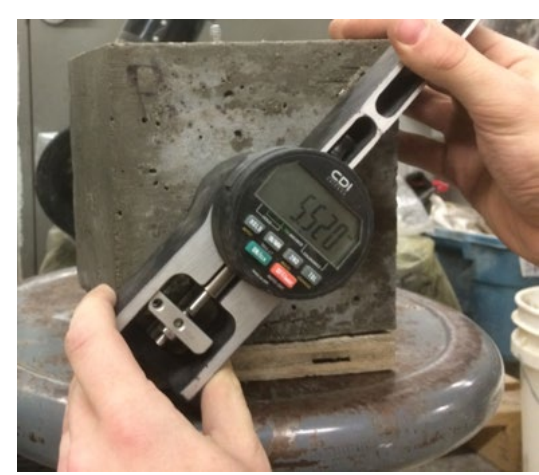

(b)

\subsubsection{Casting of Concrete Samples}

Concrete samples were cast according to CSA A23.2-14A [10] at a water-to-cementing materials ratio of 0.42 and coarse-to-fine aggregate ratio of $60: 40$ by mass. The coarse aggregate gradation is composed of three equal masses of sizes between $19.5 \mathrm{~mm}$ to $13.2 \mathrm{~mm}, 13.2 \mathrm{~mm}$ to $9.5 \mathrm{~mm}$, and $9.5 \mathrm{~mm}$ to $4.75 \mathrm{~mm}$. The cementitious materials mass is $420 \mathrm{~kg} / \mathrm{m}^{3}$, and the alkalinity of the cement was boosted to $1.25 \% \mathrm{Na}_{2} \mathrm{O}_{\mathrm{e}}$, using $\mathrm{NaOH}$, as per CSA A23.2-14A [10]. The cubes were cast in three layers where each layer was rodded 25 times using a standard rod of rounded end with a diameter of $10 \mathrm{~mm}$. The cylinders were cast in four layers to allow good consolidation along with the height; each layer was rodded with 25 strokes. The samples were demolded after 24 hours. Zero readings were taken, and then the samples were put above water in their designated containers lined with cloth at $38^{\circ} \mathrm{C}$. The buckets used for the prisms/cylinders ( $\varnothing$ 257 by $375 \mathrm{~mm})$ and the cube containers $(213 \times 191 \times 197 \mathrm{~mm})$ are shown in Fig. 4.

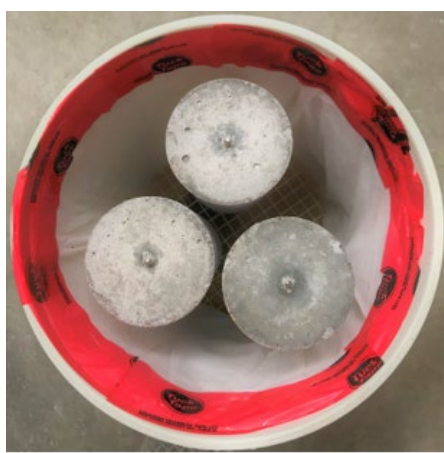

(a)

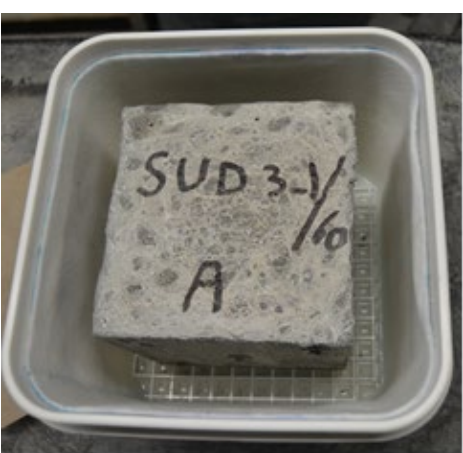

(b)

Fig. 4. Storage containers for (a) cylinders/prisms, and (b) cubes [5].

\subsection{3. $\quad$ Alkali Leaching}

Alkalis leached from concrete samples to the bottom of the containers were measured at 1.5 years. At the age of testing, the solution at the bottom of the containers was collected to obtain its volume and a $10 \mathrm{~mL}$ 
sample was taken for measurements. Concentrations of $\mathrm{Na}^{+}$and $\mathrm{K}^{+}$ions were obtained by flame photometry. The results are then converted to $\mathrm{Na}_{2} \mathrm{O}_{e}$ and reported as a percent of the sample's initial 1.25\% $\mathrm{Na}_{2} \mathrm{O}_{\mathrm{e}}$ content by mass of Portland cement.

\subsubsection{Alkali Release from Aggregates}

To examine the alkali release characteristics of the different aggregates, $100 \mathrm{~g}$ samples constituted of $50 \mathrm{~g}$ passing $4.75 \mathrm{~mm}$ sieve and retained on $2.36 \mathrm{~mm}$ sieve, and $50 \mathrm{~g}$ passing $2.36 \mathrm{~mm}$ sieve and retained on $1.18 \mathrm{~mm}$ sieve were prepared. This size fraction has been used because a gradation between $1.25 \mathrm{~mm}$ and $5.0 \mathrm{~mm}$ was recommended as it allows a reasonable acceleration for the actual alkali release and maintains the microstructural characteristics of coarse aggregates compared to finer size aggregates that might overestimate the alkali release [19]. The dry samples were then soaked in solutions of different alkalinities: $0.25 \mathrm{M} \mathrm{NaOH}, 0.25 \mathrm{M} \mathrm{KOH}, 0.70 \mathrm{M} \mathrm{NaOH}$ and $0.70 \mathrm{M} \mathrm{KOH}$. The concentrations of $\mathrm{Na}^{+}$and $\mathrm{K}^{+}$ions were measured in $\mathrm{KOH}$ and $\mathrm{NaOH}$ solutions, respectively. In addition, aggregate samples were also soaked in distilled water and the soluble alkalis were determined. The ratio of aggregates to solution used was 1:1, similar to an earlier study by Bérubé et al. [18]. Samples were maintained at $38^{\circ} \mathrm{C}$, with some being agitated to accelerate the release of alkalis. After 4 weeks, $2 \mathrm{~mL}$ samples from the soaking solution were taken for measurements of $\mathrm{Na}^{+}$and $\mathrm{K}^{+}$ions using flame photometry. Three samples from each type of aggregate were prepared and the average was reported as $\mathrm{Na}_{2} \mathrm{O}$ and $\mathrm{K}_{2} \mathrm{O}$ taken as a percent of the aggregate mass. The aggregate samples - soaked in solution - were then put back at $38^{\circ} \mathrm{C}$ and subsequent measurements were done once every 4 weeks.

\subsection{5. $\quad$ Relative Humidity Test}

Relative humidity in the specimens' core was monitored using a Rapid RH Easy Reader, allowing measurements of temperature and RH. Rapid RH 4.0 EX smart sensors of $40 \mathrm{~mm}$ length were installed in the center of the samples, with $10 \mathrm{~mm}$ extensions added to increase the length of the sensor barrel in the case of the cylinders and cubes. Samples were cast using the same procedure as the samples used for expansion measurements. A pre-made hole was molded using a piece of foam of the same diameter as the sensor and with a length equal to half the sample's thickness $(75 \mathrm{~mm}$ and $37.5 \mathrm{~mm}$ for the cubes and prisms, respectively). After 24 hours, the samples were demolded, and the piece of foam was taken out to allow the installation of the sensors instead. For the cylindrical samples, it was not possible to place the foam before casting since drilling a hole in the cylindrical molds along their diameters was not easy. Therefore, after demolding, a hole was drilled to the center of the samples using a $19 \mathrm{~mm}$-diameter drill bit, cleaned, and then the RH sensor was installed. Readings of relative humidity inside the samples were done every day for the first month and then once per week.

\section{Results}

\subsection{Expansion of Concrete Samples}

The expansions up to two years of the three different sample shapes containing Sudbury and Spratt aggregates, without SCM, are presented in Fig. 5. The cylinders cast with Sudbury and Spratt both showed higher expansion than the prisms while the cubes had similar expansion to that of the prisms. The 1-year prism expansions of concrete with Sudbury and Spratt were $0.17 \%$ and $0.21 \%$, respectively. 


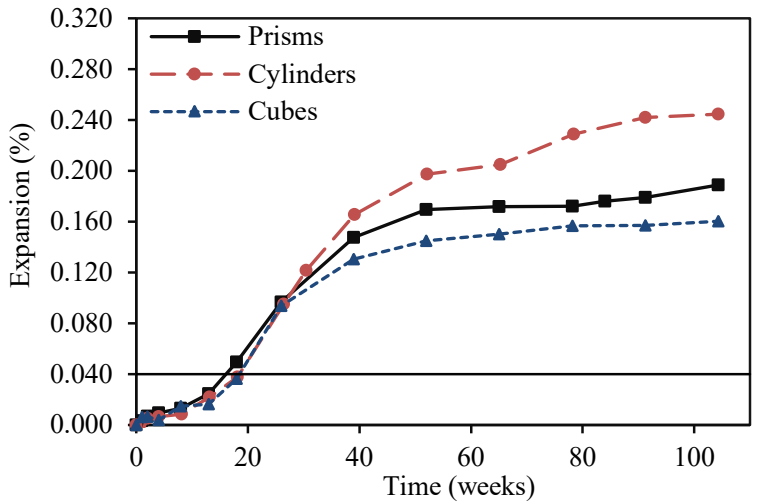

(a)

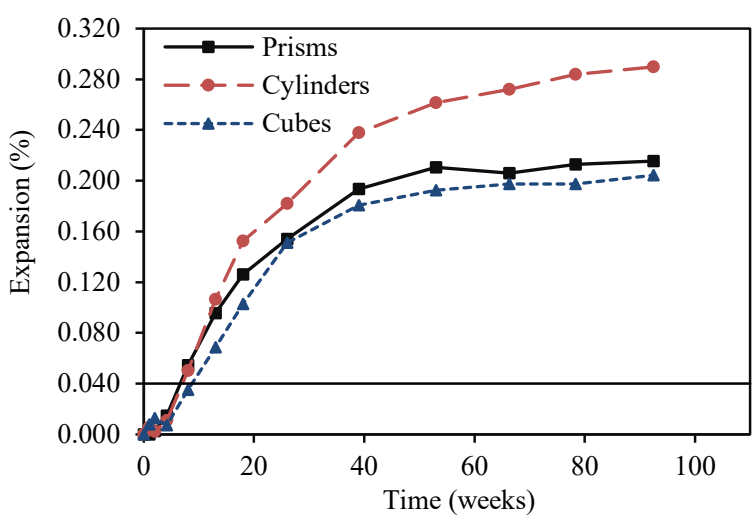

(b)

Fig. 5. Expansion at $38^{\circ} \mathrm{C}$ for concrete samples containing (a) Sudbury and (b) Spratt aggregates.

For samples with SCM, the results obtained for Sudbury samples with 15\% FA and 25\% slag are presented in Fig. 6, showing higher expansion for cylinders compared to prisms or cubes. With $25 \%$ slag, the prisms had a 2 -year expansion below $0.040 \%(0.037 \%)$, passing the concrete prism test. Looking at the cylinders at 2 years, they had an expansion above $0.040 \%(0.064 \%)$ or failed to pass the CPT expansion criterion of $0.040 \%$. Similarly, with $15 \%$ FA, the prisms had an expansion way below $0.040 \%(0.017 \%)$, while the cylinders were about to fail at 2 years with an expansion value of $0.037 \%$. Based on the tested samples, the cylinders provide higher expansion than prisms and, in some cases, can lead to a different conclusion in terms of pass/fail the CPT expansion criterion when used with Sudbury aggregate.

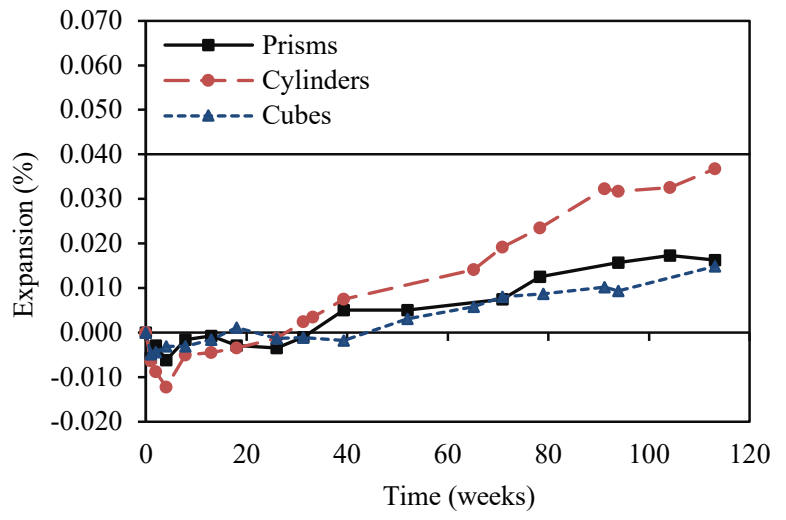

(a)

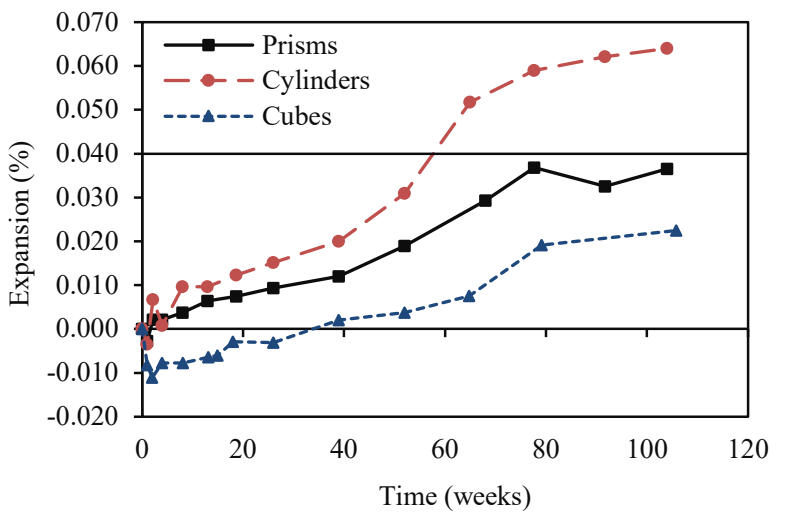

(b)

Fig. 6. 2-year expansion at $38^{\circ} \mathrm{C}$ of concrete containing Sudbury aggregate with (a) $15 \%$ FA and (b) $25 \%$ Slag.

For Spratt aggregate with SCM, the expansion data for samples with $15 \%$ and $20 \%$ FA are presented in Fig. 7. Replacing cement by $20 \%$ Class F FA was found to be the minimum required level to pass the concrete prism test for Spratt aggregate. This was shown in Fig. 7(b), where prisms had an expansion below $0.040 \%(0.035 \%)$ as compared to the samples with 15\% FA (Fig. 7(a)), which had an expansion above $0.040 \%(0.053 \%)$. The same conclusions were obtained with the cylinders as the cylinders and prisms had similar expansions in this case, although cylinders with $15 \%$ FA showed slightly higher expansion. Spratt samples with SCM showed a different trend than the Sudbury samples with SCM where the latter clearly showed higher expansion for cylinders compared to prisms. Spratt samples with $35 \%$ and $50 \%$ slag were tested, and results are presented in Fig. 8. 


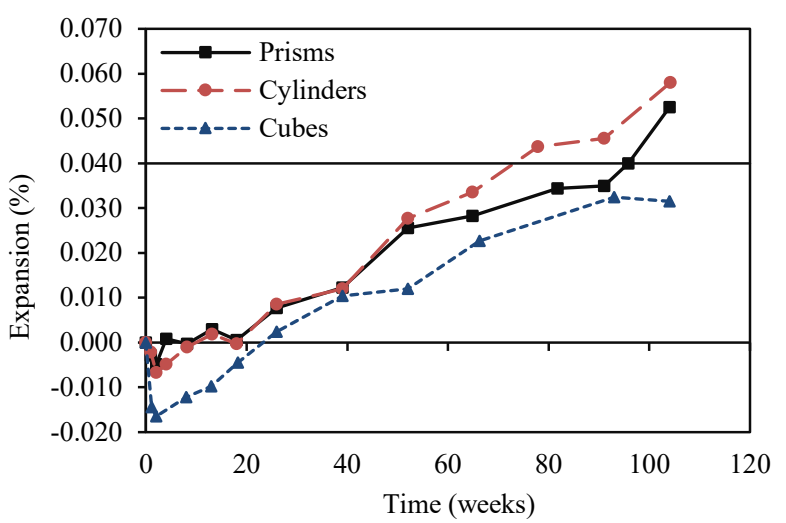

(a)

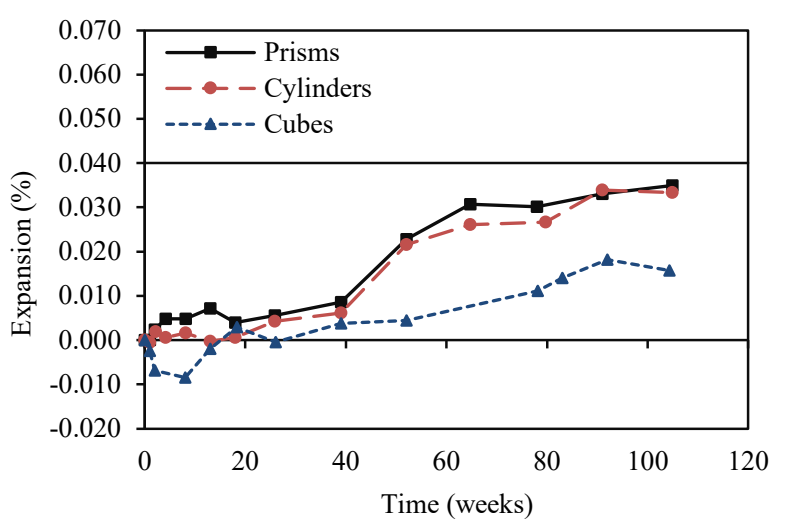

(b)

Fig. 7. 2-year expansion at $38^{\circ} \mathrm{C}$ of concrete containing Spratt aggregate with (a) $15 \%$ FA and (b) $20 \%$ FA.

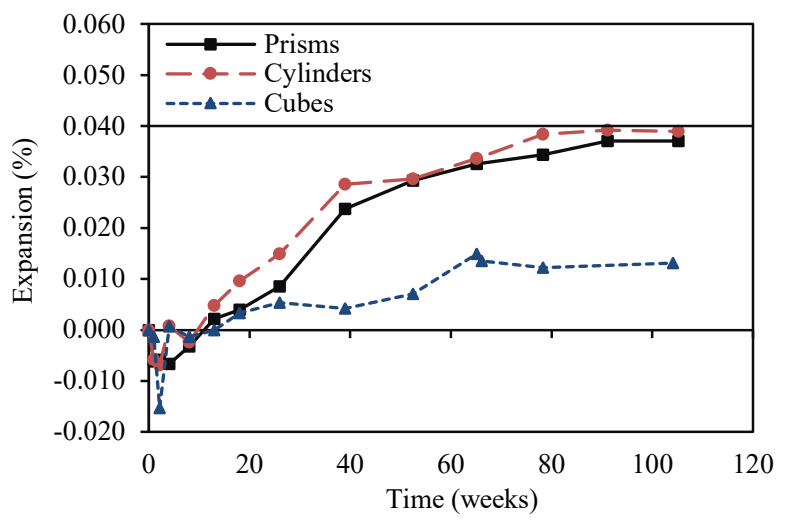

(a)

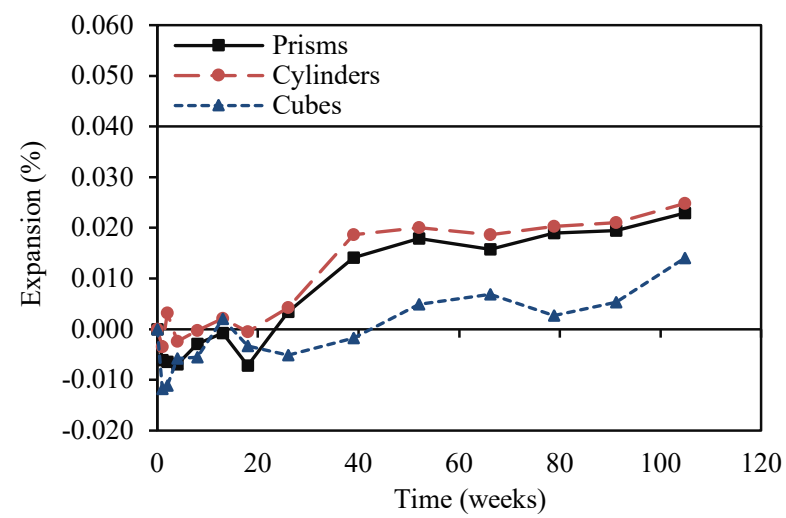

(b)

Fig. 8. 2 -year expansion at $38^{\circ} \mathrm{C}$ of concrete containing Spratt aggregate with (a) $35 \%$ slag and (b) $50 \%$ slag.

It is clear from Fig. 7 and Fig. 8 that prisms and cylinders have similar expansions with all the different combinations of Spratt and SCM, which was not the case with Sudbury aggregates. Similar results for Spratt samples with GUB-8SF were obtained. Spratt prisms and cylinders cast with GUB-8SF showed same expansion of $0.039 \%$ at 2 years when tested using the CPT. Similarly, Spratt prisms cast with GUB-8SF and $20 \%$ FA showed an expansion of $0.011 \%$ at 2 years which is very close to the cylinders' expansion of $0.015 \%$.

Fig. 9 shows a comparison between the expansion of prisms and that of the cylinders cast with Sudbury and Spratt aggregates at 1 year for the samples without SCM and 2 years for the samples with SCM. For Spratt, the 2-year expansions of prisms and cylinders both showed a pass/pass or fail/fail relationship. However, with Sudbury, there was a pass/fail relationship observed with one sample where the cylinders failed the $\mathrm{CPT}$ as opposed to the prisms. The other case showed pass/pass relationship; however, the cylinders were about to fail at 2 years where the prisms expansion was way below the $0.040 \%$ expansion limit. Another way to look at the results in Fig. 9 is by looking at the deviation of the points from the $45^{\circ}$ line. Spratt samples with SCM lie on the line while all Sudbury/SCM and Spratt or Sudbury without SCM lie above the line. 


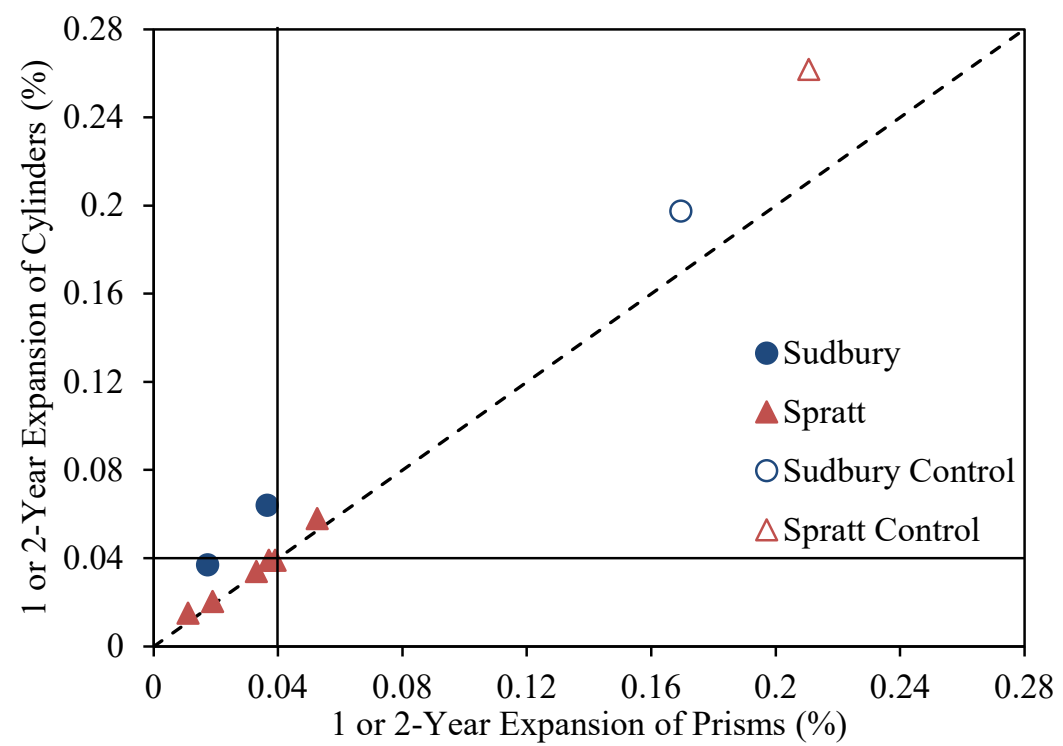

Fig. 9. Expansion of cylinders versus prisms at 1 year for samples without SCM and 2 years for samples with SCM.

\subsection{Alkali Leaching from Concrete Samples}

The leached alkalis from the different aggregates/SCM combinations for all the sample shapes were measured and results are summarized in Fig. 10 for Sudbury and Fig. 11 for Spratt. The figures show that the alkalis released from concrete with Sudbury aggregate were higher than the alkalis released from concrete with Spratt.

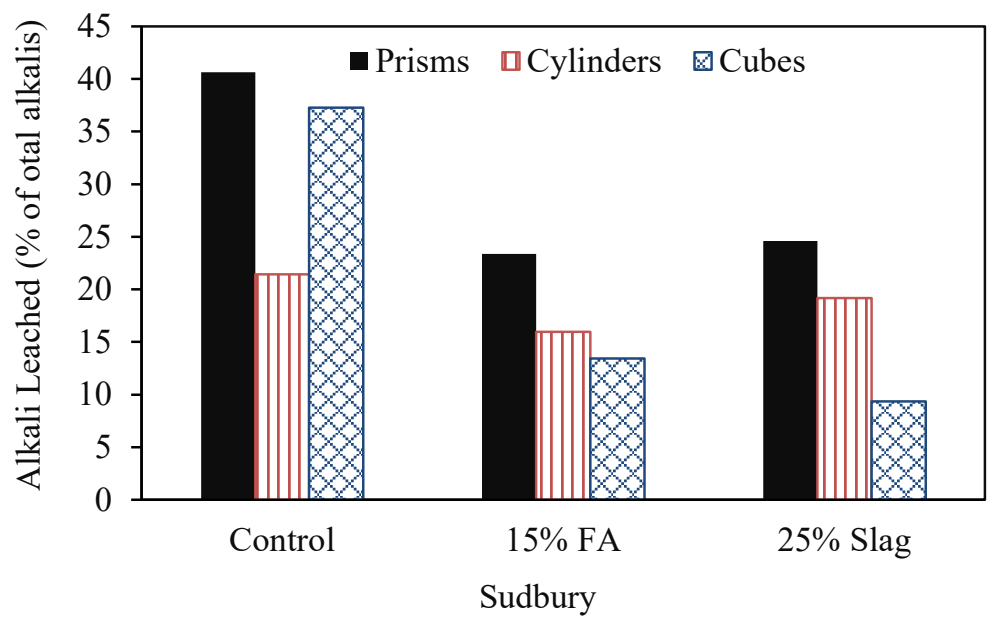

Fig. 10. Alkali leached from Sudbury samples measured at 1.5 years. 


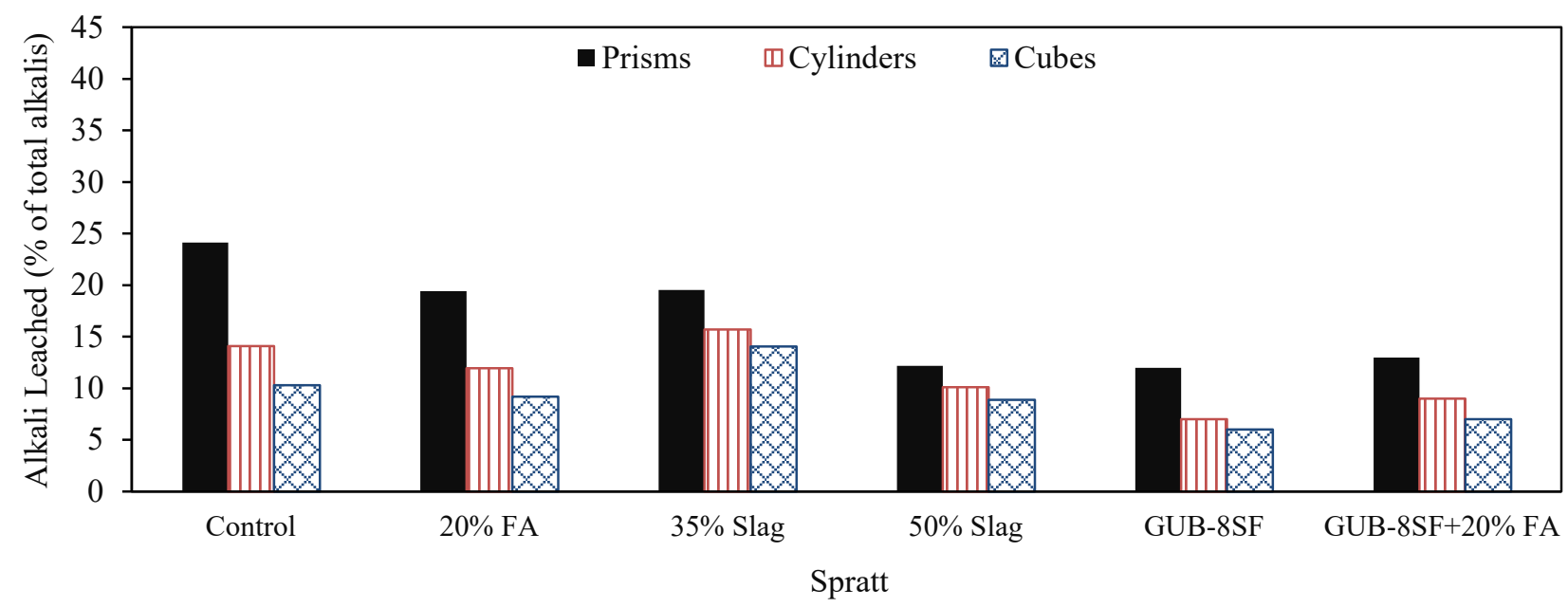

Fig. 11. Alkali leached from Spratt samples measured at 1.5 years.

In addition, prisms had the highest leaching, followed by cylinders and then cubes. The only exception was the case of the control sample (no SCM) with Sudbury, where the cubes had an alkali leaching higher than that of the cylinders. The reasons behind this are not known. However, with all the other tested samples, leaching was the highest with the prisms compared to cylinders and cubes. Thus, more leaching occurred with smaller samples, as was also reported by Sinno and Shehata [5], Bérubé et al. [15], and Lindgård et al. [16]. Accordingly, it is expected to see higher expansion with cylinders compared to prisms which was the case with Sudbury but not Spratt/SCM combinations. Possible reasons for this are included in the Discussion subsection of this paper.

The difference in the amount of alkalis leached from concrete with Spratt (24\%) and that with Sudbury (41\%) could be explained, at least partly, by the fast reactivity of Spratt and its associated alkali consumption. The rate of expansion between 4 and 18 weeks for Spratt was four times higher than the Sudbury samples. This was obtained by calculating the slopes of the curves between 4 and 18 weeks in Fig. 5, showing the fact that Spratt reacts faster than Sudbury. The fast reactivity of Spratt could have used more alkalis, leaving less free alkalis in the concrete pore solution available to be leached. In addition to the difference in the reaction rate, the higher level of alkalis released from the aggregate itself - Sudbury compared to Spratt - might help explain the difference in the amount of leached alkalis between concrete with Spratt and Sudbury as explained in Section 3.3.

\subsection{Alkali Release from Aggregates}

Alkali release from aggregates was obtained in different alkaline solutions. The $\mathrm{Na}^{+}$and $\mathrm{K}^{+}$ions released were measured in $\mathrm{KOH}$ and $\mathrm{NaOH}$ solutions, respectively. Measuring $\mathrm{Na}^{+}$in $\mathrm{KOH}$ solution makes it easy to trigger changes in $\mathrm{Na}^{+}$concentration of the solution and the same is applicable to measuring $\mathrm{K}^{+}$in $\mathrm{NaOH}$ solution. The presented results correspond to the average of three samples and are shown in Fig. 12 and Fig. 13 for Sudbury and Spratt, respectively. The $0.70 \mathrm{M}$ solution represents concrete pore solution before significant expansion takes place while the $0.25 \mathrm{M}$ solution represents alkalinity after significant expansion has occurred $[9,23]$. The dashed lines represent the samples that have been agitated during the test duration. 


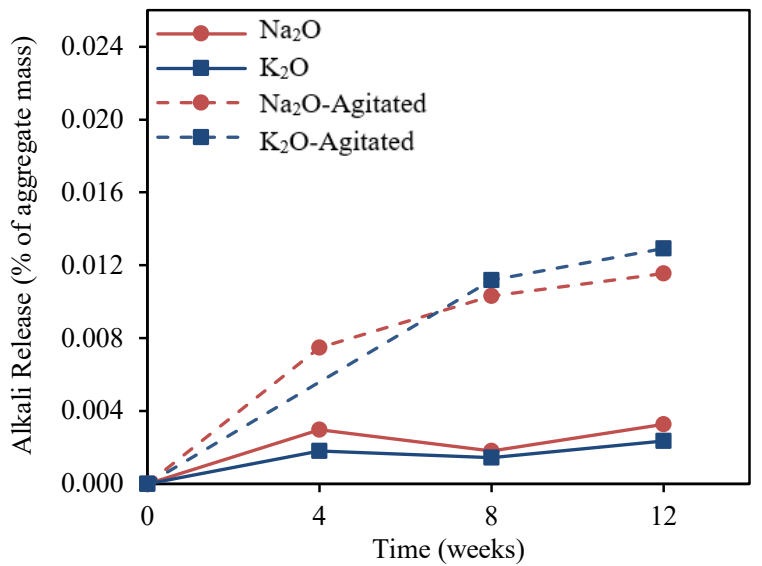

(a)

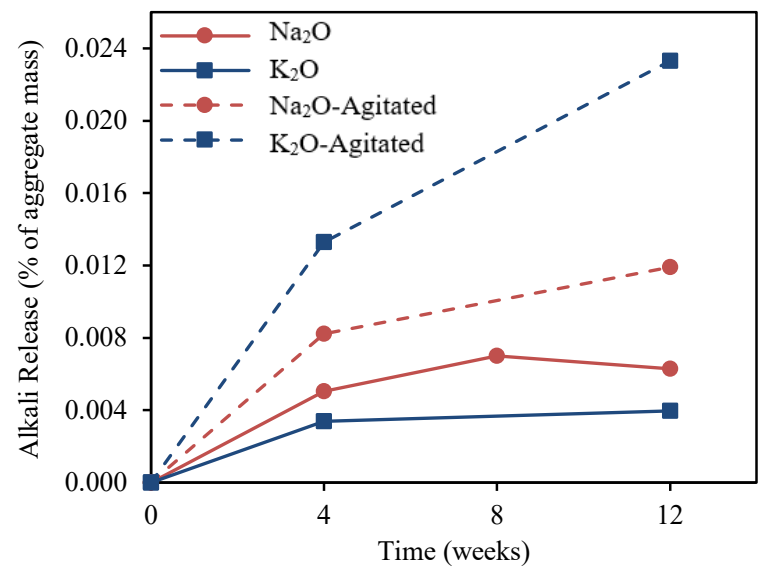

(b)

Fig. 12. Alkali release from Sudbury aggregate at $38^{\circ} \mathrm{C}$ in alkaline solution of (a) $0.25 \mathrm{M}$ and (b) $0.70 \mathrm{M}$.

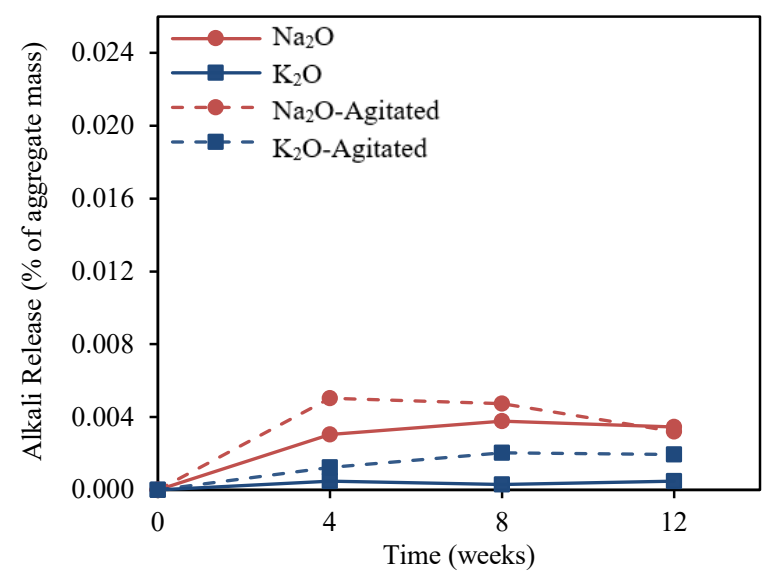

(a)

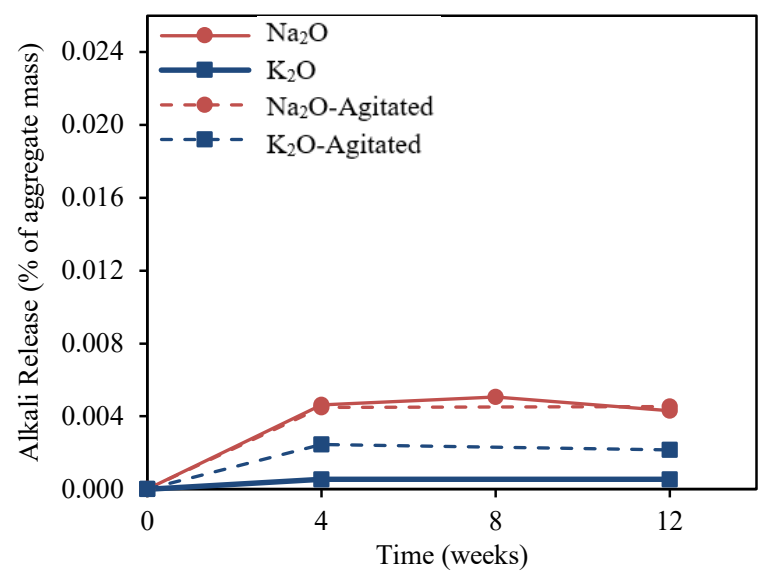

(b)

Fig. 13. Alkali release from Spratt aggregate at $38^{\circ} \mathrm{C}$ in alkaline solution of (a) $0.25 \mathrm{M}$ and (b) $0.70 \mathrm{M}$.

As expected, the release of alkalis from aggregates was found to be accelerated when samples are being agitated during the testing period. Sudbury aggregate released a higher amount of alkalis compared to Spratt. This might be due to the higher total alkali content in Sudbury aggregate compared to Spratt. Sudbury and Spratt aggregates have a total alkali content of $4.35 \%$ and $0.09 \% \mathrm{Na}_{2} \mathrm{O}_{\mathrm{e}}$ by aggregate mass, respectively [18]. This could partly explain the increased leaching obtained with concrete containing Sudbury compared to concrete with Spratt.

In $0.70 \mathrm{M}$ solutions, more release of alkalis was obtained compared to samples soaked in $0.25 \mathrm{M}$ solutions. This is in line with Bérubé et al. [18] who found that there was more release of alkalis in $0.7 \mathrm{M}$ solutions compared to saturated lime solutions. On the contrary, Yujiang et al. [20] found very minimal release of alkalis into $0.7 \mathrm{M} \mathrm{NaOH}$ and $\mathrm{KOH}$ solutions and larger contributions when aggregates were soaked in saturated $\mathrm{Ca}(\mathrm{OH})_{2}$ solutions. It should be noted that the aggregates used in the two studies - [18] and [19] - were not the same.

In the current study, samples were also tested in distilled water, in addition to the $0.25 \mathrm{M}$ and $0.70 \mathrm{M}$ solutions, and it was shown that the amount of soluble alkalis is lower than the alkalis released in $\mathrm{NaOH}$ and $\mathrm{KOH}$ solutions. At 12 weeks, Sudbury released $0.0012 \% \mathrm{Na}_{2} \mathrm{O}$ and $0.0007 \% \mathrm{~K}_{2} \mathrm{O}$ by aggregate mass. For Spratt, there was an alkali release of $0.0009 \% \mathrm{Na}_{2} \mathrm{O}$ and $0.0005 \% \mathrm{~K}_{2} \mathrm{O}$ by aggregate mass. Hence, the results in this study showed that the released alkalis increase in solutions of higher alkalinity. 
The effect of solution alkalinity on alkalis released from aggregates can help explain the higher expansion of cylindrical samples with Sudbury, compared to prisms. Since concrete cylinders were found to leach less compared to prisms, the pore solution alkalinity is expected to be higher with the cylinders. Hence, more alkali release from aggregates might be obtained, especially with the Sudbury aggregate contributing to the observed difference in expansion between prisms and cylinders. For Spratt samples, the contribution of alkalis to the pore solution is very minimal even when aggregates were shaken and soaked in $0.70 \mathrm{M}$ solutions. In other words, the alkalis released from Spratt is very low regardless of the alkalinity of the host solution.

\subsection{Relative Humidity Inside the Cores}

Relative humidity measurements were done using humidity probes to see whether the larger cross-section has an effect on relative humidity inside the samples. Fig. 14 shows the RH data obtained on two different samples: one with Spratt and the other with Spratt and 25\% FA for prisms, cylinders, and cubes. The vertical lines correspond to the day of length measurements; i.e., samples were taken out from the $38^{\circ} \mathrm{C}$ room and put at $23^{\circ} \mathrm{C}$ for length measurements.

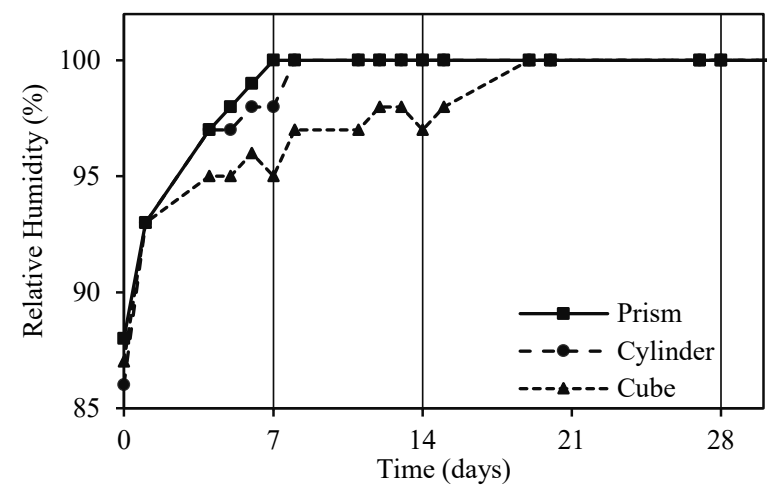

(a)

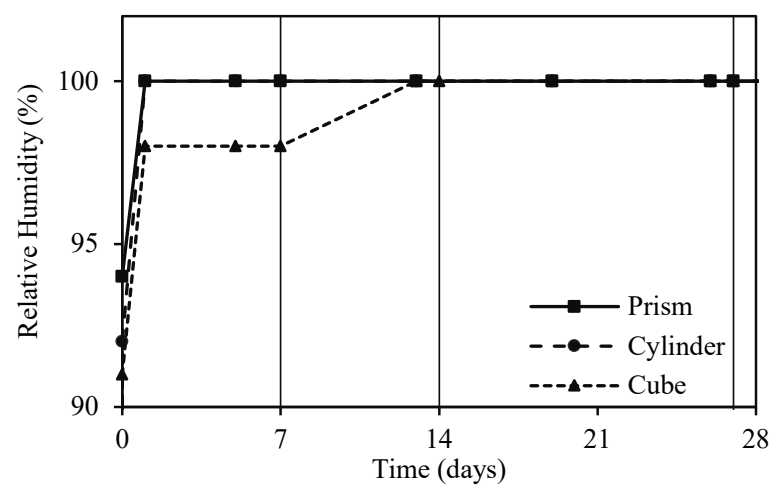

(b)

Fig. 14. Relative humidity measurements of Spratt samples (a) without SCM and (b) with $25 \%$ FA.

For both samples, it is clear that the prisms and cylinders reach $100 \%$ humidity faster than the cubes. For samples without SCM, the cubes took 3 weeks longer to reach $100 \%$ humidity and to catch up with the prisms and cylinders. For the samples with SCM, the cubes took 2 weeks to reach $100 \%$ RH. However, by 21 days, the relative humidity reached $100 \%$ and the cubes did not seem to be affected by being taken out of the heat room. In other words, the difference in expansion obtained with the three sample shapes cannot be attributed to the difference in relative humidity within the samples.

\section{Relationship Between Laboratory and Field Expansions}

The expansion results obtained here are compared to those from field samples to see if a particular lab sample geometry/size correlates better than others to field samples. The field sample results are obtained from the literature [12-14]. The field blocks were $0.4 \times 0.4 \times 0.7 \mathrm{~m}$ cast using the same mix design as the CPT in terms of cementing materials content $\left(420 \mathrm{~kg} / \mathrm{m}^{3}\right)$ and coarse aggregate volume ratio of 0.6 [12]. The water to cementing materials ratio was between 0.36 to 0.42 , which is close to the ratio used in this study (0.42) [14]. Sudbury and Spratt aggregate cast with Class F FA or silica fume were also investigated in the field blocks. Expansion measurements were taken until 15 years and reported $[12,13]$. The only difference between lab and field mixtures is the use of air-entraining admixtures for the outdoor exposure blocks, which is not the case for the samples cast in the laboratory. The samples referred to in this section were placed in CANMET outdoor site located in Ottawa, Ontario. 
Field blocks with no added alkali at 10 years showed a good correlation with the CPT at 2 years for all the different aggregates studied by Fournier et al. [14]. However, at 15 years, Ideker et al. [12] reported discrepancies between field and laboratory expansions with the outdoor blocks showing higher than anticipated expansion with some aggregates/SCM combinations.

Fournier et al. [14] reported Sudbury samples with 20\% Class F FA to show expansion at 2 years of $0.008 \%$ using the CPT and $0.023 \%$ in the field at 15 years [12]. While both values are in agreement in terms of showing expansion $<0.040 \%$, it is evident that the 15 -year field expansion of blocks is higher than the 2year CPT expansion for this type of aggregate/SCM combination. With $15 \%$ Class F FA, the field block samples - not investigated in Ideker et al. [12] and Fournier et al. [13,14] - are expected to have an expansion higher than $0.023 \%$ (expansion of samples with $20 \%$ FA) at 15 years. In this current study, prisms cast with Sudbury and $15 \%$ FA showed expansion of $0.016 \%$ while the cylinders had higher expansion and were about to fail the test $(0.037 \%)$, which is in agreement with the expected field expansion $(>0.023 \%)$.

In addition to field blocks, Fournier et al. [14] cast $0.7 \times 0.7 \times 0.15 \mathrm{~m}$ slabs with the same mix design and exposure conditions as the blocks. Sudbury samples with $20 \%$ Class F FA passed the CPT at 2 years $(0.008 \%)$ but showed an expansion in the field slabs at 10 years of $0.039 \%$ [14]. Hence, with $15 \% \mathrm{FA}$, the field slab samples are expected to have an expansion higher than $0.039 \%$ at 10 years. In the current study, Sudbury prisms containing $15 \%$ FA showed a 2 -year expansion of $0.016 \%$ while that of the cylinders was $0.037 \%$, correlating much better to the expansion of the field slabs.

It should be noted that the expansions of field slabs were higher than that of the blocks at 10 years. The reason for this as explained in [14] is the low expansion obtained on the sides of the blocks compared to the surface due to exposure of the surface to higher moisture. The reported block expansions were the average of four longitudinal measurements, two taken on the top and two on the sides of the blocks.

\section{Discussion}

In terms of alkali leaching, concrete cast with Sudbury, a moderately reactive aggregate, leached more alkalis compared to samples cast with Spratt, a highly reactive aggregate. This could be due to (1) higher alkali content and alkali release from Sudbury, which contribute to the increase of the total alkalis in the concrete samples leading to more leaching, and (2) the slow reactivity of Sudbury - as was shown from the lower rate of expansion during the first 18 weeks - leaving more alkalis free to be leached out. The cylinders were found to leach less alkalis compared to prisms which is attributable to their smaller surface area-tovolume ratio. The reduced alkali leaching from cylinders coupled with high alkali release from Sudbury could be the main reason why cylinders have higher expansion than prisms in the case of Sudbury. Moreover, the lower leaching from cylinders makes its pore solution alkalinity higher compared to prisms which may have led to further alkali release from the aggregate, especially alkali-bearing aggregates such as Sudbury. The reason for aggregates to release more alkalis to solutions of higher alkalinity is that high $\mathrm{pH}$ helps attacking the reactive silica and hence liberating alkalis from the aggregate $[25,26]$. The increased amount of hydroxyl ions present in the solution will favor the breakdown of the siloxane bonds $\left(\equiv \mathrm{Si}^{-} \mathrm{O}^{-}\right)$in the glass, which will be then occupied by $\mathrm{H}^{+}, \mathrm{Na}^{+}$or $\mathrm{K}^{+}$ions $[25,26]$. Both aggregates tested here showed higher alkali release in solutions of higher alkalinity. For Spratt, there was a difference in expansion between prisms and cylinders for the samples without SCM which is supported by the difference in alkali leaching. For Spratt/SCM combinations, there was no difference in expansion between cylinders and prisms. The limited alkali contribution from Spratt coupled with the capacity of the SCM to bind alkalis could have made the difference in pore solution alkalinity between cylinders and prisms not as high as the case with Sudbury aggregate. It should be noted that when marginal level of SCM is used with Spratt; i.e. $15 \%$ FA, the cylinders showed slightly higher expansions than that of prisms (Fig. 7), likely due to the limited capacity of this level of SCM to bind the extra alkalis in the pore solution of the cylinders. 
Other than the aggregate type, some factors can contribute to lower alkali leaching of cylinders compared to prisms. First, the lower the volume ratio of air-to-samples could have reduced the leaching, as reported by Bérubé et al. [15] and Costa et al. [17]. In the current research, the containers used for prisms and cylinders were the same. The volume of concrete samples when using three cylinders is higher than that when using three prisms, leading to a lower ratio for the cylinders. This could have contributed to the reduced leaching in cylinders. For the cubes, the volume ratio of air-to-concrete is lower than that of the cylinders leading to a further reduction in the cubes' leaching.

In terms of expansion, the orientation of the casting plane was reported to affect the results, i.e. the expansion due to ASR is always greater in the direction perpendicular to the casting plane [21]. Cylinders, which are cast vertically, are expected to give higher axial expansion than prisms, which are cast horizontally. This is due to the larger exposed surface area of the reactive flat and elongated particles in the direction of the casting plane [21]. Spratt was found to have higher flat and elongated particles compared to Sudbury (Tables 1 and 2). However, the expansions of cylinders and prisms with the Spratt aggregate/SCM were similar, showing that the orientation of the casting plane is not a significant factor in determining ASR expansion, at least in this study. Finally, although the volume of the cylinders is higher, it was shown that the relative humidity of the cylinders was almost $100 \%$ most of the time. The cubes showed the lowest alkali leaching due to their larger volume; however, they did not show expansion higher than the cylinders. The reasons are still being studied, but it might be due to inaccuracy in the measurements or to expansion restraint produced because of the cubes' geometric shapes. The fact that cubical field blocks showed lower expansion than slabs in [14] might support the hypothesis that the sample shape has an effect on expansion. This requires further investigation.

The above factors favor the use of cylinders compared to prisms due to the fact that the leaching is reduced and higher expansion can be obtained. It is evident from this study that the use of cylinders can be beneficial in providing better correlation with larger samples under field exposure for slowly reactive aggregates and/or for aggregates that release a significant amount of alkalis. However, more work is needed to cover different aggregates and a wide range of preventive measures.

\section{Conclusions}

The following conclusions can be drawn from this study:

1) The prisms used in the CPT have excessive leaching compared to larger volume samples, cubes, or cylinders. With the use of cylinders, reduced leaching was achieved, favoring, in some cases, higher ASR expansion.

2) For the two aggregates tested here, one aggregate was found to release more alkalis to test solutions representing concrete pore fluid. The alkalis contributed from the aggregate were higher in solutions of higher alkalinity.

3) Cylindrical samples seem to correlate better with the field samples due to their benefits in increasing expansion in the laboratory, especially with slowly reactive aggregates and/or aggregates that release a significant amount of alkalis to concrete pore solution. However, more samples should be tested to confirm the applicability of the above findings to a wider range of aggregates/SCM combinations.

4) The cubes did not show higher expansion than that of the cylinders, although they - cubes - had the lowest leaching.

\section{Acknowledgments}

Funding for this research project is obtained through a discovery grant from the Natural Sciences and Engineering Research Council of Canada (NSERC). The financial support of NSERC is highly appreciated. 


\section{References}

[1] R.N. Swamy, The alkali-silica reaction in Concrete, Taylor \& Francis, Abingdon, UK, 1992. doi:10.4324/9780203332641.

[2] J. Lindgård, Ö. Andiç-Çakir, I. Fernandes, T.F. Rønning, M.D.A. Thomas, Alkali-silica reactions (ASR): Literature review on parameters influencing laboratory performance testing, Cem. Concr. Res. 42 (2012) 223-243. doi:10.1016/j.cemconres.2011.10.004.

[3] F. Rajabipour, E. Giannini, C. Dunant, J.H. Ideker, M.D.A. Thomas, Alkali-silica reaction: Current understanding of the reaction mechanisms and the knowledge gaps, Cem. Concr. Res. 76 (2015). doi:10.1016/j.cemconres.2015.05.024.

[4] N. Sinno, M. Shehata, Development of enhanced test methods to evaluate alkali-silica reaction in concrete, in: 5th Int. Mater. Spec., Canadian Society for Civil Engineering, London, ON, 2016.

[5] N. Sinno, M. Shehata, Understanding the factors affecting expansion due to alkali-silica reaction in concrete, in: 7th Int. Mater. Spec., Canadian Society for Civil Engineering, Fredericton, ON, 2018.

[6] FHWA, Alkali-aggregate reactivity workshops for engineers and practitioners, 2012.

[7] M.H. Shehata, M.D.A. Thomas, Effect of fly ash composition on the expansion of concrete due to alkali-silica reaction, Cem. Concr. Res. 30 (2000) 1063-1072. doi:10.1016/S0008-8846(00)002830 .

[8] M. Thomas, B. Fournier, K. Folliard, J. Ideker, M. Shehata, Test methods for evaluating preventive measures for controlling expansion due to alkali-silica reaction in concrete, Cem. Concr. Res. 36 (2006) 1842-1856. doi:10.1016/j.cemconres.2006.01.014.

[9] S. Kandasamy, M.H. Shehata, The capacity of ternary blends containing slag and high-calcium fly ash to mitigate alkali silica reaction, Cem. Concr. Compos. 49 (2014) 92-99. doi:10.1016/j.cemconcomp.2013.12.008.

[10] CSA A23.2-14A, Potential expansivity of aggregate (procedure for length change due to alkaliaggregate reaction in concrete prisms at $38^{\circ} \mathrm{C}$ ), CSA, Toronto, Canada, 2014.

[11] ASTM C1293, Standard test method for determination of length change of concrete due to alkalisilica reaction, ASTM International, West Conshohocken, PA, 2018.

[12] J.H. Ideker, T. Drimalas, A.F. Bentivegna, K.J. Folliard, B. Fournier, M.D.A. Thomas, R.D. Hooton, C.A. Rogers, Importance of outdoor exposure site testing, in: 14th Int. Conf. Alkali Aggreg. React., Austin, Texas, 2012.

[13] B. Fournier, A. Bilodeau, N. Bouzoubaa, P.-C. Nkinamubanzi, Field and laboratory investigations on the use of fly ash and Li-based admixtures to prevent ASR in concrete, in: 6th Int. Conf. Durab. Concr. Struct., Leeds, UK, 2018.

[14] B. Fournier, P.C. Nkinamubanzi, R. Chevrier, Comparative field and laboratory investigations on the use of supplementary cementing Materials to control alkali-silica reaction in concrete, in: 12th Int. Conf. Alkali-Aggregate React., Beijing, China, 2004.

[15] M. Bérubé, B. Fournier, T. Côté, Testing concrete cores for residual expansion due to AAR-an attempt to minimize alkali leaching and consequent unrealistic expansion decrease, in: 14th Int. 
Conf. Alkali Aggreg. React., Austin, Texas, 2012.

[16] J. Lindgård, M.D.A. Thomas, E.J. Sellevold, B. Pedersen, Ö. Andiç-Çakir, H. Justnes, T.F. Rønning, Alkali-silica reaction (ASR) - Performance testing: Influence of specimen pre-treatment, exposure conditions and prism size on alkali leaching and prism expansion, Cem. Concr. Res. (2013). doi:10.1016/j.cemconres.2013.05.017.

[17] U. Costa, T. Mangialardi, A.E. Paolini, Minimizing alkali leaching in the concrete prism expansion test at $38{ }^{\circ} \mathrm{C}$, Constr. Build. Mater. 146 (2017). doi:10.1016/j.conbuildmat.2017.04.116.

[18] M.A. Bérubé, J. Duchesne, J.F. Dorion, M. Rivest, Laboratory assessment of alkali contribution by aggregates to concrete and application to concrete structures affected by alkali-silica reactivity, Cem. Concr. Res. 32 (2002) 1215-1227. doi:10.1016/S0008-8846(02)00766-4.

[19] D. Lu, X. Zhou, Z. Xu, X. Lan, M. Tang, B. Fournier, Evaluation of laboratory test method for determining the potential alkali contribution from aggregate and the ASR safety of the ThreeGorges dam concrete, Cem. Concr. Res. 36 (2006) 1157-1165. doi:10.1016/j.cemconres.2006.01.004.

[20] W. Yujiang, D. Min, T. Mingshu, Alkali release from aggregate and the effect on AAR expansion, Mater. Struct. Constr. 41 (2008) 159-171. doi:10.1617/s11527-007-9227-z.

[21] N. Smaoui, M. Bérubé, B. Fournier, B. Bissonnette, Influence of specimen geometry, orientation of casting plane, and mode of concrete consolidation on expansion due to ASR, Cem. Concr. Aggregates. 26 (2004) 58-70. doi:10.1520/CCA11927.

[22] C.A. Rogers, C.A. MacDonald, The geology, properties and field performance of alkali-aggregate reactive Spratt, Sudbury and Pittsburg aggregate distributed by the Ontario Ministry of Transportation, in: 14th Int. Conf. Alkali Aggreg. React, Austin, Texas, 2012.

[23] M.H. Shehata, M.D.A. Thomas, The role of alkali content of Portland cement on the expansion of concrete prisms containing reactive aggregates and supplementary cementing materials, Cem. Concr. Res. (2010). doi:10.1016/j.cemconres.2009.08.009.

[24] G. Richards, A study into the effects of test variables on the results of concrete tests for salt scaling and alkali-silica reaction, Ryerson University, 2017.

[25] R.W. Douglas, T.M. El-Shamy, Reaction of glasses with aqueous solutions, J. Am. Ceram. Soc. 50 (1967) $1-8$.

[26] R.K. Dhir, T.D. Dyer, M.C. Tang, Alkali-silica reaction in concrete containing glass, Mater. Struct. Constr. 42 (2009) 1451-1462. doi:10.1617/s11527-008-9465-8. 